\title{
Transgene expression in Penaeus monodon cells: evaluation of recombinant baculoviral vectors with shrimp specific hybrid promoters
}

\author{
Jayesh Puthumana • Rosamma Philip • \\ I. S. Bright Singh
}

Received: 19 December 2014/ Accepted: 27 March 2015/Published online: 17 May 2015

(C) Springer Science+Business Media Dordrecht 2015

\begin{abstract}
It has been realized that shrimp cell immortalization may not be accomplished without in vitro transformation by expressing immortalizing gene in cells. In this process, efficiency of transgene expression is confined to the ability of vectors to transmit gene of interests to the genome. Over the years, unavailability of such vectors has been hampering application of such a strategy in shrimp cells. We report the use of recombinant baculovirus mediated transduction using hybrid promoter system for transgene expression in lymphoid cells of Penaeus monodon. Two recombinant baculovirus vectors with shrimp viral promoters (WSSV-Ie1 and IHHNV-P2) were constructed (BacIe1-GFP and BacP2-GFP) and green fluorescent protein (GFP) used as the transgene. The GFP expression in cells under the control of hybrid promoters, $\mathrm{PH}-$ Ie1 or PH-P2, were analyzed and confirmed in shrimp cells. The results indicate that the recombinant baculovirus with shrimp specific viral promoters (hybrid)
\end{abstract}

J. Puthumana · I. S. Bright Singh ( $\square)$

National Centre for Aquatic Animal Health, Cochin University of Science and Technology, Fine Arts Avenue, Kochi 682016, Kerala, India

e-mail: isbsingh@gmail.com

R. Philip

Department of Marine Biology, Microbiology and Biochemistry, Cochin University of Science and Technology, Fine Arts Avenue, Kochi 682016, Kerala, India can be employed for delivery of foreign genes to shrimp cells for in vitro transformation.

Keywords Transgene expression - Penaeus monodon - Shrimp specific vectors · Hybrid promoter . Baculoviral vectors

\section{Introduction}

Research over the last few decades pointed out that shrimp cell line development would not be possible unless otherwise in vitro transformation through immortalizing genes were brought about. To accomplish this objective shrimp specific expression vectors turn out to be the essential requirements. Various methods have been used to deliver such vectors carrying foreign genes into eukaryotic cells, which include both physicochemical (electroporation and bombardment with gold or wolfram microparticles) and biological (lipid conjugates in the form of liposomes and recombinant viruses) techniques (Beljelarskaya 2011). Among them, viral vectors have been proven to be the most efficient tools for genetic modification of majority of somatic cells in vitro and in vivo (Sarkis et al. 2000). On this line, many viral vectors have been developed and widely used in gene transfer (transduction) and expression. To put together, they have been adenoviral (Kozarsky and Wilson 1993; Huard et al. 1995), retro and lentiviral (Naldini 
et al. 1996; Felder and Sutton 2009; Poluri et al. 2003), adeno-associated viral (Hermonat and Muzyczka 1984; Carter 2005) and baculoviral (Zeng et al. 2009) vectors. Among them, the baculovirus has emerged as the most promising gene delivery system in recent years (Lo et al. 2009). In every such case, efficiency of the viral mediated transduction and transgene expression is depended on the ability of the viral particle to transmit their genome into the nuclei.

Baculoviruses have been under investigation since 1920s as biopesticides (Black et al. 1997). After a long history, in 1985, first successful in vitro gene transfer by a recombinant baculovirus was accomplished by Carbonell et al. (1985) that made baculovirus a tool in gene transfer technology, especially in the over expression of cloned genes (O'Reilly et al. 1992). Since then, the recombinant baculoviruses have been successfully used for gene transfer in various eukaryotic cells including those of fishes (Smith and Summers 1989; Leisy et al. 2003; Wagle and Jesuthasan 2003; Wagle et al. 2004), chicken and duck (Ping et al. 2006; Song et al. 2006), fruit fly (Oppenheimer et al. 1999; Lee et al. 2000), honey bees (Ando et al. 2007), shrimp (Lu et al. 2005; Syed Musthaq et al. 2009; Syed Musthaq and Kwang 2011) rabbit (Airenne et al. 2000), monkey (Tani et al. 2001) and human (Hofmann et al. 1995; Kost and Condreay 2002). Besides, recombinant baculovirus has been used for gene therapy (Luo et al. 2011; Zhao et al. 2012), and vaccine production (van Oers 2006; Treanor et al. 2007; Hu et al. 2008; Cox 2012). More recently, Gamble and Barton (2011) expressed human telomerase reverse transcriptase (TERT) in primary fibroblasts and extended their replicative lifespan in vitro using recombinant baculovirus.

As primary shrimp cells are sensitive to standard gene delivery systems such as liposome-based transfection and electroporation, transduction mediated by recombinant baculovirus (having shrimp viral promoters) has been found an ideal proposition for transgenic expression in shrimp cells in vitro. Accordingly, recombinant baculovirus constructs were generated, that carried expression cassettes consisting of the gene encoding GFP as reporter gene (transgene) linked either to WSSV Ie1 or IHHNV P2 promoter as crustacean (shrimp) specific transduction vectors, and evaluated. These versatile transduction systems were designed with a vision to develop cell lines from shrimp through the delivery of immortalizing gene, development of DNA vaccines to crustaceans against viruses, and specific pathogen resistant or multiple pathogen resistant crustaceans through transgenesis.

\section{Materials and methods}

Plasmid vectors used

P2 complete Fluc pGL3 basic vector containing P2 promoter region of the infectious hypodermal and hematopoietic necrosis virus (IHHNV) (Dhar et al. 2007) was kindly received from Dr. Arun K. Dhar, Viracine Therapeutics Corporation (Columbia, MD, USA). pEGFP-N1 vector containing the gene encoding the green fluorescent protein (GFP) was obtained from Clontech (Mountain View, CA, USA) and pFastBac $1^{\mathrm{TM}}$ containing the polyhedrin $(\mathrm{PH})$ promoter and DH10Bac ${ }^{\mathrm{TM}}$ containing bacmid and helper plasmids were obtained from Invitrogen, Carlsbad, CA, USA. All plasmids were transformed into respective $E$. coli hosts and maintained as glycerol stock at $-80{ }^{\circ} \mathrm{C}$ (New Brunswick Scientific, Tollesbury, Maldon, England).

Crustacean specific putative promoter from WSSV and IHHNV

The WSSV-Ie1 (hereafter Ie1) basic promoter (Liu et al. 2005; Lu et al. 2005) was amplified through PCR from $P$. monodon challenged with WSSV (White spot syndrome virus) through intramuscular injection (Sudheer et al. 2011). The putative P2 promoter of IHHNV (here after P2) was PCR amplified from the P2 complete Fluc pGL3 basic vector (Dhar et al. 2007) containing the $\mathrm{P} 2$ promoter. The Ie1 basic promoter region from -1 to -512 was PCR amplified using the primer set ( $\mathrm{BamH}$ I site is underlined) of $\mathrm{F}-5^{\prime}$-GGA TCC TCC CTA CGT ATC AAT TTT ATG TGG $\overline{\text { CTA }}$ ATG GAG A-3' and R- 5'-GGA TCC ACG CGT CGA CCT TGA GTG GAG AGA GAG CTA GTT ATA A-3' (Lu et al. 2005). P2 complete pGL3 vector (Dhar et al. 2007) was used for the PCR amplification of putative the $\mathrm{P} 2$ promoter region using the primer set NP602F-5'GGA TCC CTG CGA GCG CTT CGC AG-3' and NP602R- 5'-GGATCC TAG CAC TTG GAA TAG CCT CTT-3' (BamH I site is underlined). The $25 \mu \mathrm{l}$ PCR mixture (New England Biolabs (NEB), Hitchin, UK) containing $2.5 \mu \mathrm{l} 10 \times$ standard Taq 
reaction buffer $(100 \mathrm{mM}$ Tris- $\mathrm{HCl}, 500 \mathrm{mM} \mathrm{KCl}$ and $\left.15 \mathrm{mM} \mathrm{MgCl}_{2}\right), 2.5 \mu \mathrm{ldNTP}(2.5 \mathrm{mM}), 1 \mu \mathrm{l} \mathrm{Taq}$

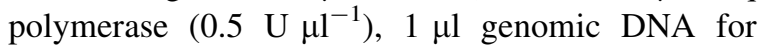
WSSV-Ie1 promoter and $0.2 \mu$ plasmid DNA (P2 complete PGL3) for IHHNV-P2 promoter ( $75 \mathrm{ng}$ ), $1 \mu \mathrm{l}$ each primer $\left(10 \mathrm{pmol} \mu \mathrm{l}^{-1}\right)$, and the mixture was made up to $25 \mu \mathrm{l}$ with ultrapure water. The hot start PCR programme used for the amplification was $95{ }^{\circ} \mathrm{C}$ for $5 \mathrm{~min}$ followed by hold at $80{ }^{\circ} \mathrm{C}, 32$ cycles of denaturation at $94{ }^{\circ} \mathrm{C}$ for $30 \mathrm{~s}$, annealing at $58{ }^{\circ} \mathrm{C}$ for $30 \mathrm{~s}$, extension at $72{ }^{\circ} \mathrm{C}$ for $2 \mathrm{~min}$, followed by final extension at $72{ }^{\circ} \mathrm{C}$ for $10 \mathrm{~min}$. Amplified products were ligated with pGEM-T Easy vector (Promega, Madison, WI, USA) by following the manufacturer's instruction. The purified pGEM-T plasmid vectors containing Ie1 (pGEMT-Ie1) and P2 (pGEMT-P2) promoter were restriction digested with $\mathrm{BamH}$ I (New England Biolabs (NEB)) to release the corresponding promoter sequences (Ie1 and P2) and were gel purified using GenElute ${ }^{\mathrm{TM}}$ Gel Extraction kit (Sigma, St. Louis, MO, USA) by following the manufacturer's instruction.

Construction of the versatile recombinant bacmid shuttle vector systems with hybrid promoters and GFP

The pFASTBac $1^{\mathrm{TM}}$ transfer vector was restriction digested with BamH I and was CIP (Calf Intestinal Phosphatase) treated following manufacturer's instruction (NEB). The product was gel purified using GenElute $^{\mathrm{TM}}$ Gel Extraction kit (Sigma, USA). The purified Ie 1 and $\mathrm{P} 2$ promoters were ligated (NEB, UK) with the restriction digested, CIP treated pFASTBac $1^{\mathrm{TM}}$ plasmid vector at $\mathrm{BamH}$ I restriction region downstream to $\mathrm{PH}$ promoter to construct two hybrid transfer vector systems such as $\mathrm{pBacIe} 1$ and $\mathrm{pBacP} 2$, respectively. The ligated products were transformed into $E$. coli $\mathrm{DH} 5 \alpha$ for its propagation.

The GFP was inserted downstream to hybrid promoter (PH-Ie1 or PH-P2) in the transfer vector system pBacIe1 and $\mathrm{pBaP} 2$, respectively. The GFP was restriction digested from pEGFP-N1 vector with Sal I and Not $\mathrm{I}(\mathrm{NEB}, \mathrm{UK})$. The vectors $\mathrm{pBacIe} 1$ and $\mathrm{pBacP} 2$ were restriction digested with SalI and NotI (NEB) and purified using GenElute ${ }^{\mathrm{TM}}$ Gel Extraction kit. The restriction digested, gel purified GFP gene was inserted to the corresponding restriction sites (SalI and NotI). Ligated products were transfected into $E$. coli DH5 $\alpha$ and the confirmed colonies were propagated for plasmid extraction.

The PH-Ie1-GFP and PH-P2-GFP cassettes in the pFastBac $1^{\mathrm{TM}}$ transfer vector along with mini-Tn7 transposone element could transposone to the miniatt-Tn7 target site of the bacmid in the presence of transposition proteins provided by the helper plasmid present in DH10Bac ${ }^{\mathrm{TM}}$ E. coli. Colonies containing recombinant bacmids were identified by antibiotic selection and blue/white screening, since the transposition resulted in disruption of the lacZ $\alpha$ gene of DH10Bac ${ }^{\mathrm{TM}}$, transformants produced white colonies. High molecular weight mini-prep DNA was prepared from selected $E$. coli clones containing the recombinant bacmid using PureLink, HiPure Plasmid Miniprep kit (Invitrogen, Darmstadt, Germany).

The orientation of bacmid DNA-carrying PH-Ie1GFP and PH-P2-GFP fragments (cassettes) were confirmed by PCR amplification using the M13F (5'CCC AGT CAC GAC GTT GTA AA ACG3') bacmid primer and GFP specific primer (NP266R-5' CAC GAA CTC CAG CAG GAC CAT G3').

\section{Generation of recombinant baculoviruses}

To generate the recombinant viruses, Sf9 cells were transfected with the confirmed bacmid DNA using Cellfectin ${ }^{\circledR}$ II reagent (Invitrogen, Grand Island, NY, USA) by following manufacturer's instruction. Briefly, an aliquot of $1 \mu \mathrm{l}\left(500 \mathrm{ng} \mathrm{ml}^{-1}\right)$ recombinant bacmid DNA was diluted with $100 \mu \mathrm{l}$ antibiotic and serum free TNM-FH medium (Sigma, USA) and mixed with Cellfectin ${ }^{\circledR}$ II which was previously diluted by adding $8 \mu \mathrm{l}$ into $100 \mu \mathrm{l}$ TNM-FH medium (antibiotics and serum free). The lipid-bacmid mixture (transfection mixture) was mixed gently and incubated at RT for $45 \mathrm{~min}$, added drop wise onto the cells and incubated at $28^{\circ} \mathrm{C}$ for $6 \mathrm{~h}$. After incubation, the transfection mixture was replaced with TNM-FH medium containing $15 \%$ fetal bovine serum (FBS) (Sigma, USA) and antibiotics (HiMedia, India) such as penicillin $\left(100 \mathrm{U} \mathrm{ml}^{-1}\right)$ streptomycin $\left(100 \mu \mathrm{g} \mathrm{m}^{-1}\right)$ and amphotericin B $\left(0.25 \mu \mathrm{g} \mathrm{ml}^{-1}\right)$. The cells were further incubated at $28{ }^{\circ} \mathrm{C}$ until the sign of viral infection (cytopathic effect (CPE)) and fluorescent signals (GFP) could be visualized.

Recombinant baculovirus released in the TNM-FH medium was collected from each culture dish and was used to re-infect another sets of Sf9 cells 
$\left(1.5 \times 10^{6}\right.$ cells ml $\left.{ }^{-1}\right)$ to amplify the viral stock. After amplification, the medium containing concentrated virus was collected in sterile centrifuge tubes and centrifuged at $500 \times g$ for 5 min to remove the cell debris. The clear supernatant was transferred to fresh cryovials, covered with aluminum foil to protect from light and stored at $-80{ }^{\circ} \mathrm{C}$ until transduction performed in lymphoid cell culture from $P$. monodon.

Analysis of hybrid promoter mediated transcriptional activity

Transcriptional activity of the recombinant baculovirus constructs that carried expression cassettes consisting of gene encoding GFP as reporter linked either to PH-Ie1 or PH-P2 hybrid viral promoter was carried out in Sf9 cells. The hybrid promoter activity of PH-Ie1 or PH-P2 cassettes in the recombinant baculovirus BacIe1-GFP and BacP2-GFP, respectively, were determined by examination of GFP (reporter gene) signals from the transduced Sf9 cells using Fluorescence-Inverted phase contrast microscope with GFP filter (Leica DMIL, Wetzlar, Germany). Transduced cells were observed every $3 \mathrm{~h}$ for $24 \mathrm{~h}$, and subsequently in every $24 \mathrm{~h}$ for 3 days for the phenotypic changes and the GFP signals. Single promoter $(\mathrm{PH})$ linked GFP cassette (PH-GFP) in recombinant baculovioral vector Bac-GFP was used as control.

Analysis of the SDS-PAGE separated GFP was performed. Post-transduced $(72 \mathrm{~h})$ Sf9 cells were harvested in $400 \mu 1 \times$ SDS-PAGE lysis buffer (62.5 mM Tris-HCl, pH 6.8, $2 \%$ SDS) and boiled for $5 \mathrm{~min}$. The extracted protein was subjected to reducing sodium dodecyl sulphate polyacrylamide gel electrophoresis (SDS-PAGE) following the method of Laemmli (1970). Protein expression was determined by comparing with the protein profile of un-transduced Sf9 cells (control). Molecular weight of the protein band was determined by comparing with that of standards (Genei, Peenya, Bangalore, India).

To assess the safety in handling recombinant baculoviruse expression system with hybrid promoters, susceptibility of human cell lines such as HeLa and HEp2 to the virus was tested.

Transduction of shrimp cells in vitro and in vivo

Recombinant baculovirus constructs that carried expression cassettes consisting of gene encoding GFP as reporter linked to the hybrid promoter either to $\mathrm{PH}-\mathrm{Ie} 1$ or PH-P2 were transduced into primary cell cultures from $P$. monodon. Cell cultures for transduction were prepared from various cell types/tissues of $P$. monodon in $35 \mathrm{~mm}$ culture dish in shrimp cell culture medium (SCCM) following Jayesh et al. (2013, 2015). After $24 \mathrm{~h}$ incubation of cell cultures at $25^{\circ} \mathrm{C}$, the medium was replaced with $1 \mathrm{ml} \mathrm{SCCM}$ and $1 \mathrm{ml}$ supernatant containing recombinant baculovirus (1:1) with an MoI 10 and incubated for $6 \mathrm{~h}$ at $25^{\circ} \mathrm{C}$, replaced with growth medium (SCCM) containing $15 \%$ FBS. GFP expression was observed, demonstrating the hybrid promoter activity in shrimp cells in vitro. Expression of GFP under the control of either of these promoter cassettes was evaluated through microscopic examination. Transduced cell cultures were observed every $3 \mathrm{~h}$ for $24 \mathrm{~h}$, and subsequently in every $24 \mathrm{~h}$ for 3 days for the phenotypic changes and the GFP signals.

For transduction of shrimp cells in vivo an aliquot of $10 \mu$ recombinant baculovirus $\left(\sim 1 \times 10^{4} \mathrm{pfu} \mathrm{ml}^{-1}\right)$ was given intramuscularly to healthy $P$. monodon (Sudheer et al. 2011). The recombinant baculovirus BacIe1-GFP and BacP2-GFP carrying expression cassettes PH-Ie1-GFP and PH-P2-GFP, respectively, were used for this experiment along with Bac-GFP as control vector ( $\mathrm{PH}$ promoter only). After injection animals were maintained under laboratory conditions for 45 days in aerated seawater of $15 \%$ salinity and followed strict bio-security norms to prevent the entry of this virus to natural ecosystem. After 45 days, the animals were sacrificed and various tissue/cells of the animals were observed for GFP expression using Inverted phase contrast fluorescence microscope (Leica).

\section{Results}

Construction of the versatile vector systems with hybrid viral promoters

Two recombinant baculoviral transduction vectors, BacIe1-GFP and BacP2-GFP that carried expression cassettes consisting of gene encoding GFP as reporter linked to the hybrid promoter either to $\mathrm{PH}-\mathrm{Ie} 1$ or $\mathrm{PH}-$ P2 were successfully constructed (Fig. 1). The transfer vector $\mathrm{pFastBac} 1^{\mathrm{TM}}$ (Invitrogen) provided the strong $\mathrm{PH}$ promoter from Autographa californica multiple 
nuclear polyhedrosis virus (AcMNPV). Either Ie1 or P2 promoter was inserted at the position 4032 (4032th base in vector map) in continuation with 128-bp sized PH promoter (3904-4032) in pFastBac $1^{\mathrm{TM}}$ transfer vector to make the hybrid promoter system (Fig. 1a, b). The 4032th site of the pFastBac $1^{\mathrm{TM}}$ transfer vector was cleaved with $\mathrm{BamH}$ I (Fig. 2a) to insert the shrimp viral promoter Ie1 or P2 with a sequence size 502-bp and 116-bp, respectively (Fig. 2b-d). Ie1 and P2 were the crustacean specific promoters from white spot syndrome virus (WSSV) and IHHNV, respectively. GFP, the reporter gene was inserted at the multiple cloning sites (4037-4142) between 4070 and 4090 position by restriction digestion with Sal I and Not I (Fig. 2e), confirming that the GFP was in-frame with hybrid promoter. A total of 20 bases were removed while replacing GFP gene sequence at this position. The results from colony PCR using forward primer of

Fig. 1 Generation of recombinant baculoviral transduction vector.

A construction of transfer vector containing hybrid promoter and GFP. $a$ GFP cassettes inserted between Sal I and Not I site in the transfer vector to construct wild-type baculovirus (control) expressing GFP; $b$ constructed transfer vector (pBacIe1-GFP) for generating recombinant baculovirus with PH-Ie1 hybrid promoter and GFP reporter; and $c$ transfer vector ( $\mathrm{pBacP} 2-\mathrm{GFP}$ ) for generating recombinant baculovirus with $\mathrm{PH}-\mathrm{P} 2$ hybrid promoter and GFP reporter gene. $\mathbf{B}$ schematic structure for the generation of recombinant baculovirus transduction vector from transfer vector

b either Ie1 or P2 and the reverse primer of GFP confirmed the alignment of insert in the transfer vector (Fig. 2f-h). The expression cassettes containing hybrid promoter, multiple cloning sites, GFP were at the position between transposon elements Tn7R and Tn7L which allowed the site specific transposition of the expression cassettes along with a gentamicin resistance gene into the baculoviral genome. Transposon mediated transposition in bacmid was confirmed using M13 (forward) and GFP (reverse) primers, indicating that the inserts were transpositioned in correct orientation (Fig. 2i).

Transduction of Sf9 cells in vitro and evaluation of transcriptional activity

The efficiency of newly designed baculovirus-mediated transduction vector in gene transfer was
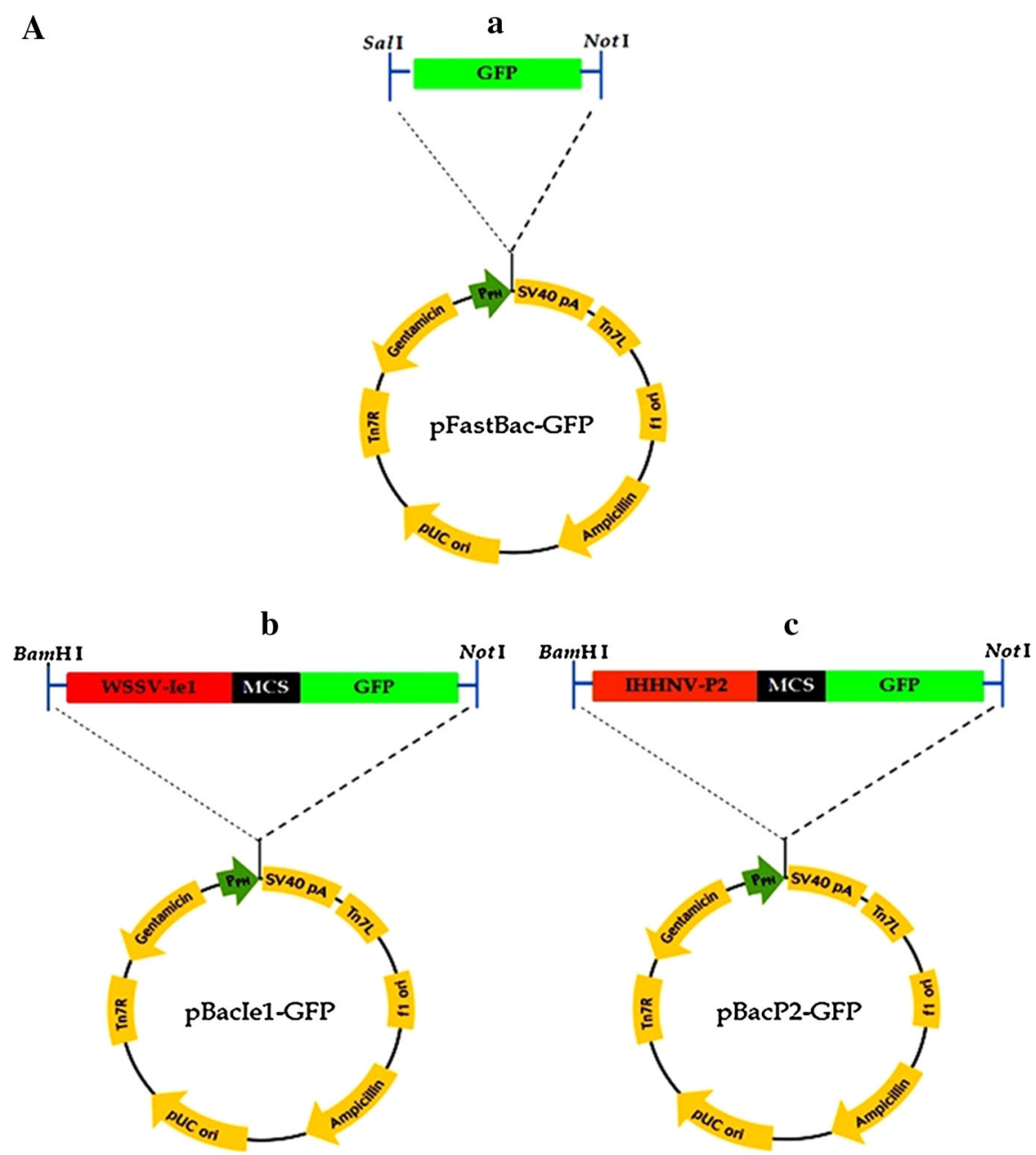


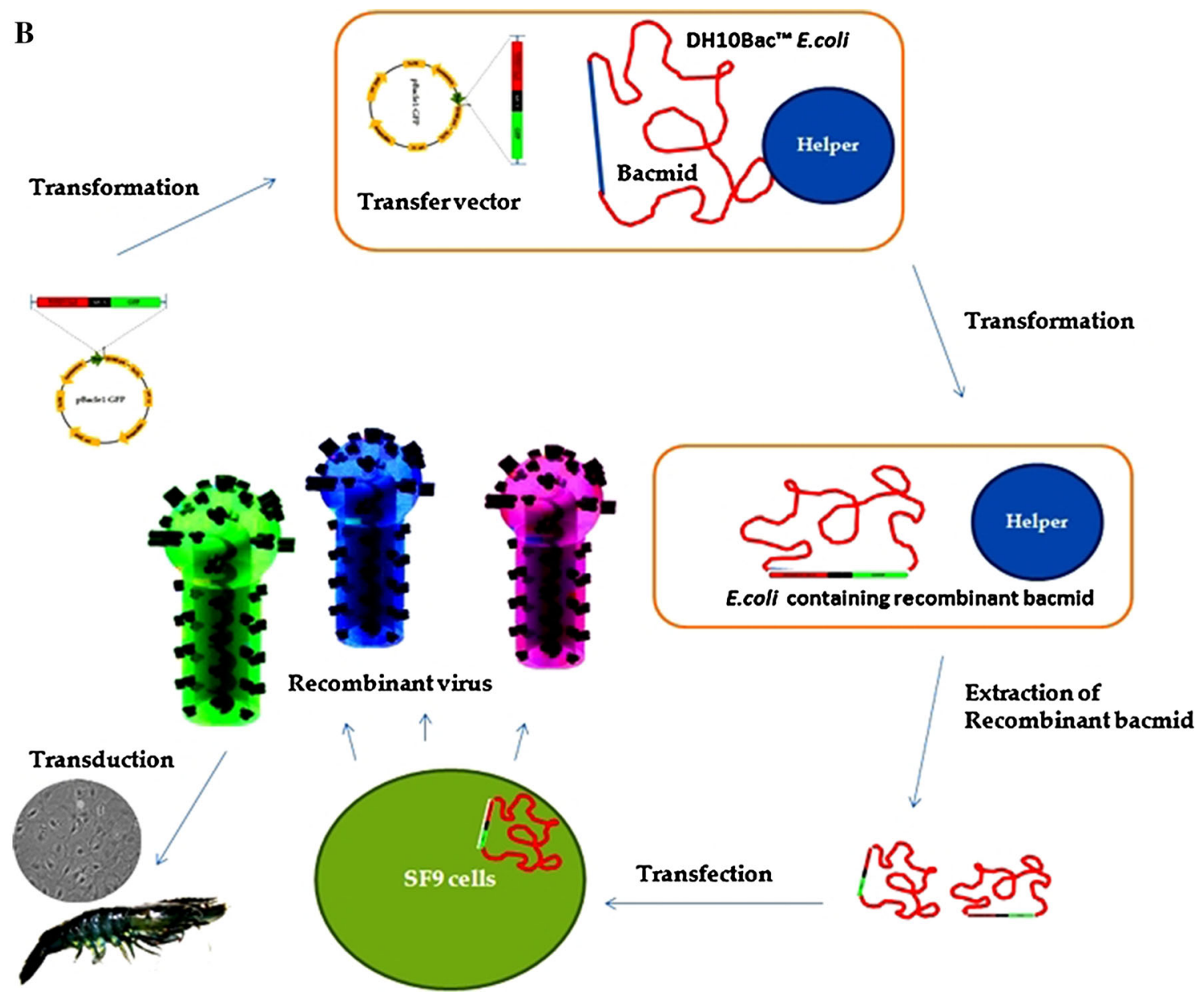

Fig. 1 continued
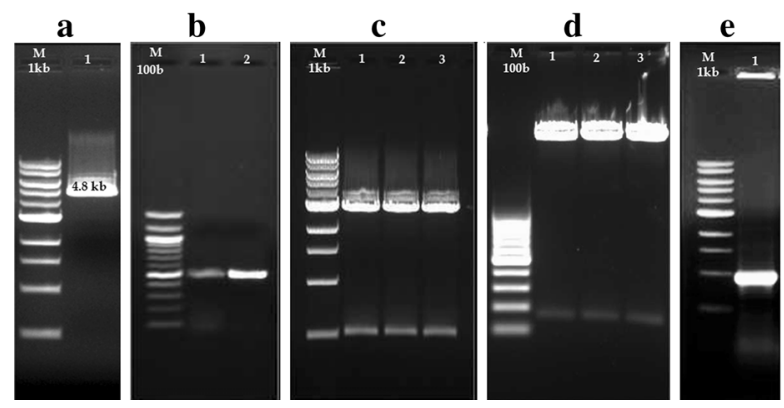

Fig. 2 Agarose gel showing, a Linearized plasmid pFastBac $1^{\mathrm{TM}}$ digested with $\mathrm{BamH} \mathrm{I}$; b PCR amplified WSSV immediate early gene (Ie1) product of 502-bp size from infected animal (lanes 1-2); c WSSV Ie1 promoter (502-bp) released from pGEM-T vector after restriction digestion with BamH I (lanes 1-3); d IHHNV P2 promoter (116-bp) released from PGEMT-T vector after restriction digestion with BamH I (lanes 1-3); e GFP gene restriction digested from pEGFP N1 with Sal I and Not I; f colony PCR performed for confirming the alignment of
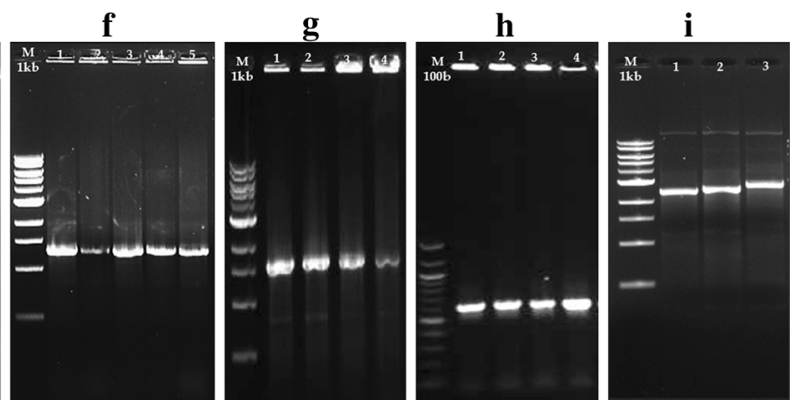

inserted GFP gene in pFastBac $1^{\mathrm{TM}}$ vector between $\mathrm{Sal} \mathrm{I}$ and $\mathrm{Not}$ I sites (lanes 1-5); g Ie1-GFP alignment confirmation using Ie1 forward primer and GFP reverse primer (lanes 1-4); h P2-GFP alignment confirmation using P2 forward primer and GFP reverse primer (lanes 1-4); i PCR confirmation of the recombinant bacmid using M13 forward and GFP reverse primers (lane 1: wild type baculovirus tagged with GFP, lane 2: recombinant bacmid with $\mathrm{P} 2$ promoter, lane 3: recombinant bacmid with Ie1 promoter) 

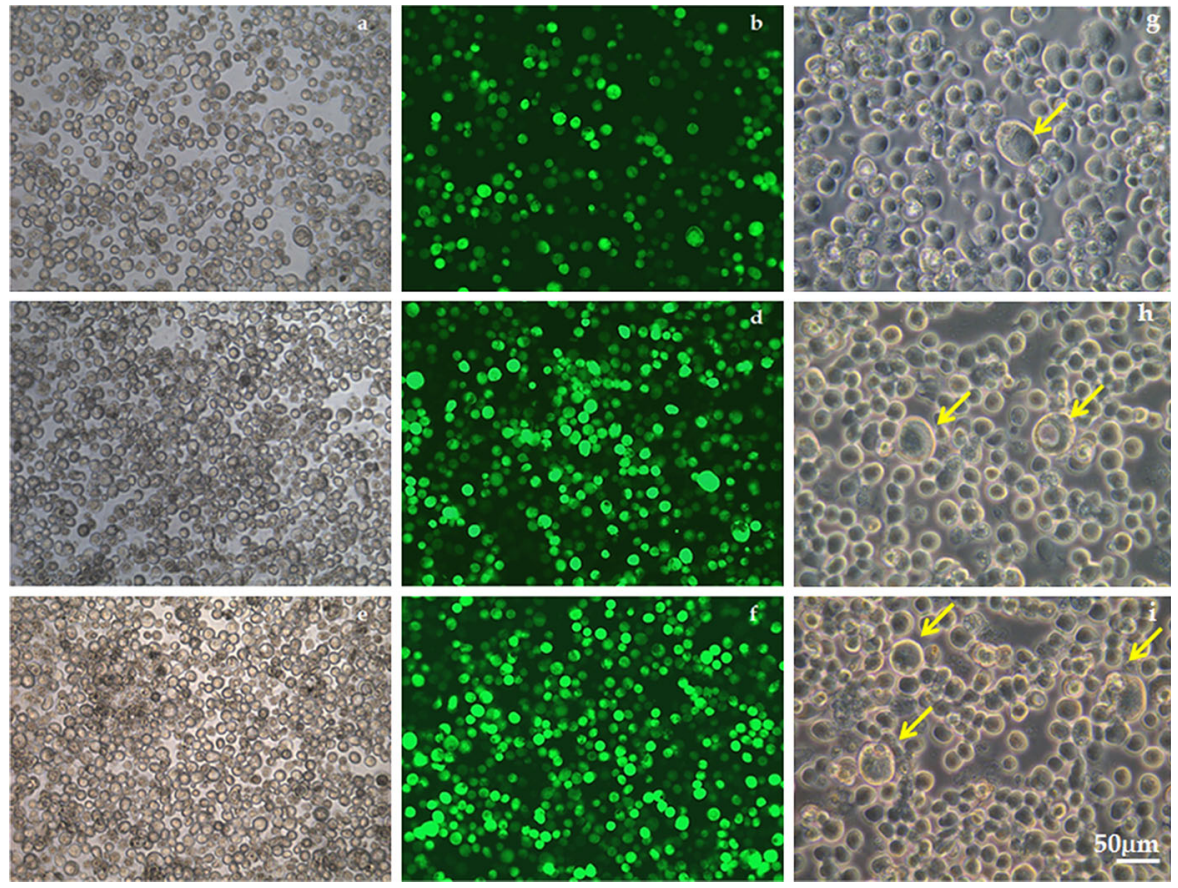

Fig. 3 Recombinant baculovirus mediated tranduction in insect cells ( $\mathrm{Sf} 9$ ). a, $\mathbf{c}$ and $\mathbf{e}$ phase contrast image of the transduced Sf9 cells with Bac-GFP, BacIe1-GFP and BacP2GFP respectively; b, d, and $\mathbf{f}$ corresponding image under fluorescence microscope. The green fluorescent signals indicate

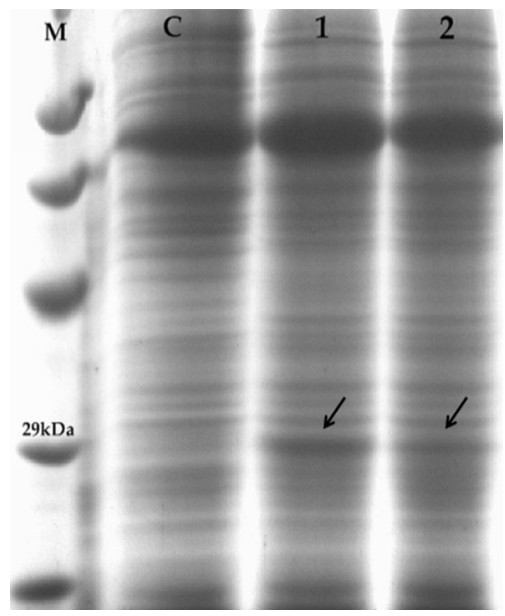

Fig. 4 SDS-PAGE analysis of reporter protein (GFP) synthesis in Sf9 cells infected with recombinant baculovirus (vector): $M$ molecular marker, $C$ control cells without infection, 1 protein expression under the control of PH-Ie1 promoter (BacIe1-GFP vector), 2 protein expression under the control of PH-P2 promoter (BacP2-GFP vector). Arrow indicates GFP the active viral transcription inside the cells. The phase contrast images $\mathbf{g}, \mathbf{h}$ and $i$ demonstrate cytopathic effect (arrow) after $12 \mathrm{~h}$ post infection with Bac-GFP, BacIe1-GFP and BacP2-GFP respectively. (Color figure online)

successfully confirmed with Sf9 cells. Baculovirusderived vector expressing the GFP reporter gene under the control of either PH-Ie1 or PH-P2 hybrid promoters were expressed, suggesting the transcriptional initiation and transduction in Sf9 cells. In the case of both transduction vectors, expression of GFP was observed in $\mathrm{Sf} 9$ cells within $6 \mathrm{~h}$ of post transduction. After $6 \mathrm{~h}$ of infection with recombinant virus, $10 \%$ of the cells expressed GFP and this increased to $20 \%$ within $12 \mathrm{~h}$ post transduction followed by $80 \%$ within $24 \mathrm{~h}$ and more or less $100 \%$ total within $32 \mathrm{~h}$. Moreover, typical baculoviral cytopathic effects were observed in $12 \mathrm{~h}$ post infected cells (Fig. 3). Furthermore, the hybrid promoter induced expression of GFP was confirmed by SDS-PAGE (Fig. 4), which had resulted in the presence of expressed protein under the control of PH-Ie1 and PH-P2 hybrid promoter cassettes in the cells transduced with recombinant virus BacIe1-GFP and BacP2-GFP respectively. Observed fluorescence intensity from transduced cells suggested 
that transcriptional activity in the Sf9 cells was more or less similar under the control of hybrid promoters, and high intensity of fluorescent signals was observed at $24 \mathrm{~h}$ post transduction. Further, the transduction efficiency and the infectivity of the recombinant virus were found to be $100 \%$ within $32 \mathrm{~h}$ post transduction with $\sim 1 \times 10^{4} \mathrm{pfu} \mathrm{ml}^{-1}$ (approximate value, suggested by the manufacturer). Sign of infection and transduction (no GFP signal) were not observed in human cell lines, HeLa and HEp2, confirming that the recombinant viral particles were not able to infect human cells (data not shown).

Transduction of shrimp cells in vitro and in vivo, and evaluation of transcriptional activity

The recombinant baculovirus BacIe1-GFP and BacP2GFP containing PH-Ie1 and PH-P2 hybrid promoter cassettes drove the expression of GFP reporter gene in shrimp cells in vitro and in vivo, demonstrated by fluorescent microscopy. However, PH-GFP (Control) expression cassettes under the control of $\mathrm{PH}$ promoter in the Bac-GFP virus did not express GFP to a detectable level. Transduction efficiency in shrimp cells with both recombinant virus BacIe1-GFP and BacP2-GFP was found to be 10-20\% in comparison to the efficiency in Sf9 cells, which was almost $100 \%$. In vivo experiments with recombinant viral vector proved that the trangene could be expressed in most of the cell/tissue types tested. The recombinant baculovirus BacIe1-GFP with PH-Ie1 hybrid promoter was active in gills, nerve ganglia, intestine, muscles, haemocytes and lymphoid organ. Whilst, recombinant baculovirus BacP2-GFP with PH-P2 hybrid promoter was more active in hepatopancreas, haemocytes, gills and lymphoid organ. In the in vitro experiments,
A
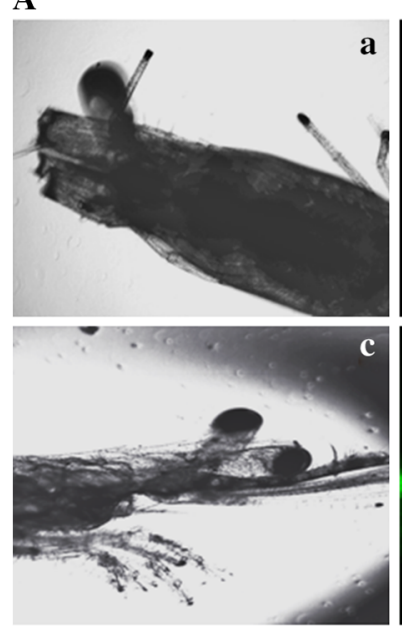

e
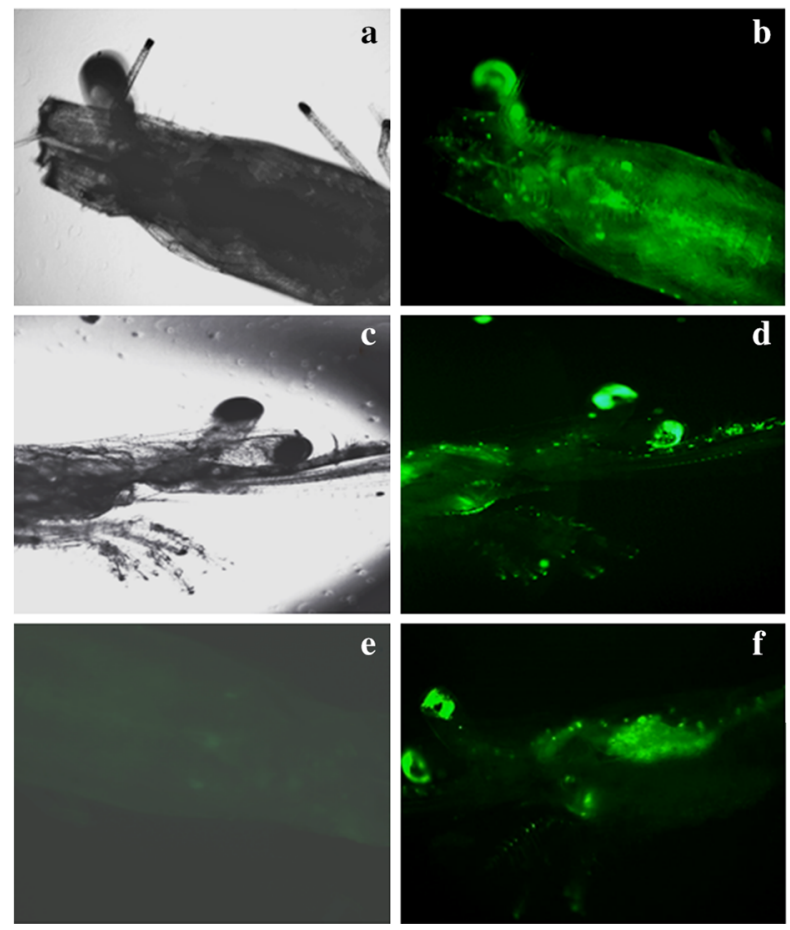

Fig. 5 Transduction of GFP expressing recombinant baculovirus in vivo in susceptible larvae of $P$. monodon 3 days post infection under microscope ( $\times 10$ magnifications). A $a$, $c$ image of gill tissue; $b$ expression of GFP from the same tissue under baculovirus containing PH-Ie1 hybrid promoter (BacIe1GFP); $b, d$ corresponding animals expressing GFP; $e$ uninfected animal, and $f$ GFP expression from animal infected with recombinant baculovirus containing $\mathrm{PH}-\mathrm{P} 2$ hybrid promoter
B

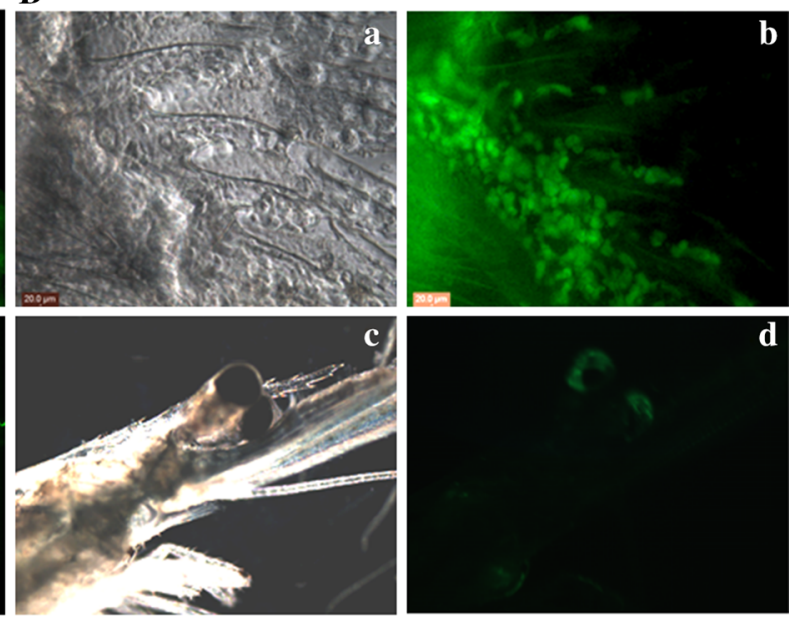

(BacP2-GFP). B expression of GFP from various gill tissue of $P$. monodon transduced with recombinant baculovirus (BacP2GFP) containing PH-P2 hybrid promoter; $a$ phase contrast image of gill tissue; $b$ expression of GFP from the same tissue under fluorescence microscope indicating the viral transcription and successful transduction; $c$ and $d$ control animal under bright field and fluorescent microscope. Low level of auto fluorescence observed in eyestalk (scale bar $20 \mu \mathrm{m}$ ) 
haemocytes, hepatopancreas, lymphoid and heart tissues were used to confirm their susceptibility to the recombinant virus particles. The $\mathrm{PH}-\mathrm{Ie} 1$ promoter system in BacIe1-GFP virus initiated transcription and expressed GFP in all cell types tested in vitro. Meanwhile, with $\mathrm{PH}-\mathrm{P} 2$ promoter system in BacP2GFP, the virus showed more activity in lymphoid cells and found more cells transduced with GFP expression than the BacIe1-GFP. In both cases, expression was observed $48 \mathrm{~h}$ post-transduction. Control animals were subjected to imaging under fluorescence microscope to avoid misinterpretation from the autofluorescence from its exoskeleton and eye stalk (Figs. 5, 6). The shrimp injected with the above recombinant viruses (BacIe1-GFP and BacP2-GFP) survived for 45 days without disease signs, suggesting the vector system nonpathogenic to the animals (Data not presented).

\section{Discussion}

Studies on the development and establishment of shrimp cell lines have been hampered by the lack of effective molecular tools for gene transfer into primary shrimp cell cultures. Because the spontaneous transformation of shrimp cells in vitro and their establishment as permanent cell lines were found cumbersome to achieve, the induced immortalization was hypothesized to be the only option left to attempt develop shrimp cell lines (Jayesh et al. 2012; Jayesh 2013). Under such a situation, vectors capable of enhanced and long term delivery of immortalizing gene to the primary shrimp cell culture are required to evade the molecular blocks that prevent in vitro transformation. Moreover, primary shrimp cells were found to be very sensitive to standard gene delivery systems especially liposome-based transfection and electroporation. Thus, for the transgenic expression, viral mediated transduction is the better choice amongst all such methods. In this context, this study describes the construction of two recombinant baculovirus vectors with shrimp virus promoters designed to transfer foreign genes into shrimp cells.

The putative promoters from shrimp viruses (WSSV-Ie1 and IHHNV-P2) such as WSSV and IHHNV have been considered for constructing recombinant baculovirus vectors (BacIe1-GFP and BacP2-GFP). Immediately early (IE) gene Ie1 of
WSSV along with ie2, and ie 3 were identified in infected shrimps (Liu et al. 2005), wherein Ie1 gene promoter has been considered as an efficient viral promoter to construct expression vectors. Moreover, WSSV Ie1 promoter was found active and controls transcription in insect, shrimp, avian and mammalian cells (Prabakaran et al. 2010; Syed Musthaq et al. 2009; He et al. 2008; Gao et al. 2007). Syed Musthaq et al. (2009) constructed a recombinant baculovirus encoding VP28 envelop protein under the control of WSSV Ie1 protein and expressed this vector in shrimp tissue. He et al. (2008) suggested that recombinant baculovirus with WSSV Ie 1 promoter was more active than with cytomegalovirus (CMV) promoter for displaying expression of haemagglutination activity of $\mathrm{H} 5 \mathrm{~N} 1$ virus.

IHHNV P2 promoter was proven to control transcription in insect, fish and crustacean cells (Dhar et al. 2007), that possessed the canonical TATA box (TATATAA). Dhar et al. (2007) demonstrated transient expression of luciferase under the control of P2 promoter in the constructed vector P2 complete pGL3, even though the results were variable. Because, it is located near map unit 2, Shike et al. (2000) named the promoter P2. In the present study, the same P2 promoter was used for constructing the recombinant baculovirus.

The recombinant baculovirus has emerged as a potent tool for protein production (Liu et al. 2010), virus generation (Zheng et al. 2010; Lesch et al. 2011), vaccine development (Madhan et al. 2010), in cancer therapy (Wang and Balasundaram 2010) and tissue engineering (Lin et al. 2010). In the present study, baculovirus vectors were used as the backbone to construct recombinant vectors with shrimp viral promoters. Additionally, Condreay et al. (1999) described the use of a recombinant baculovirus vector carrying a mammalian expression cassette comprising the CMV immediate early (CMV-IE) promoter and the gene for GFP to direct gene expression in a wide variety of mammalian cell lines as well as primary human cells derived from different tissues. Likewise, studies suggested that recombinant baculovirus vectors carrying GFP reporter gene under the control of WSSV Ie1 promoter were capable of transducing shrimp cells in vivo (Syed Musthaq et al. 2009; Syed Musthaq and Kwang 2011) and in vitro (Lu et al. 2005).

The hybrid promoter $\mathrm{PH}-\mathrm{Ie} 1$ and $\mathrm{PH}-\mathrm{P} 2$ in the recombinant baculovirus vector BacIe1-GFP and 
A
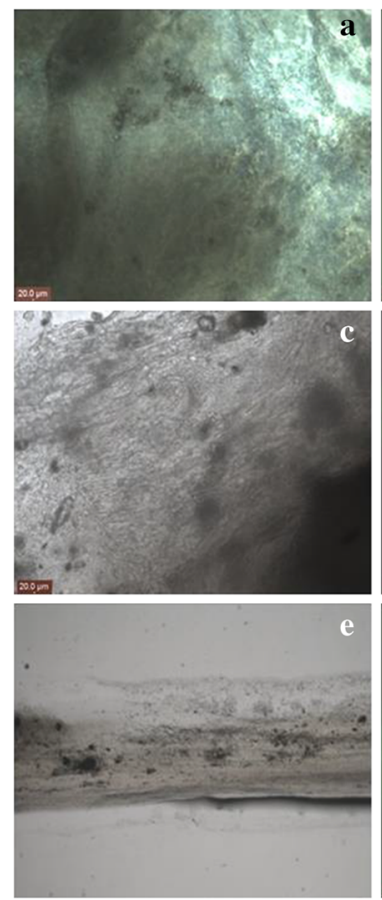

C
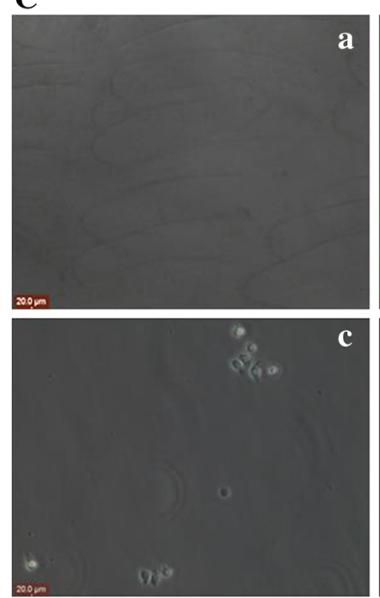

e

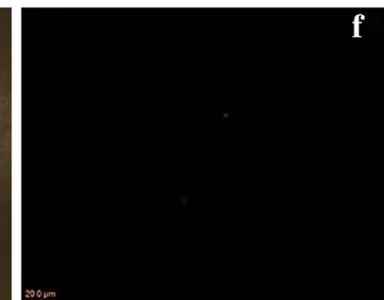

Fig. 6 Expression of GFP from various organs/tissues of $P$. monodon transduced with recombinant baculovirus containing hybrid promoter. A Expression under the control of PH-Ie1 (BacIe1GFP); $a, c$ and $e$ phase contrast images of heart, muscle and intestine, and $b, d$ and $f$ the corresponding GFP expression. $\mathrm{P} 2 \mathrm{GFP}$ ); $a, c$ and $e$ phase contrast images of heart, lymphoid organ B Expression under the control of PH-P2 hybrid promoter (Bac-

B
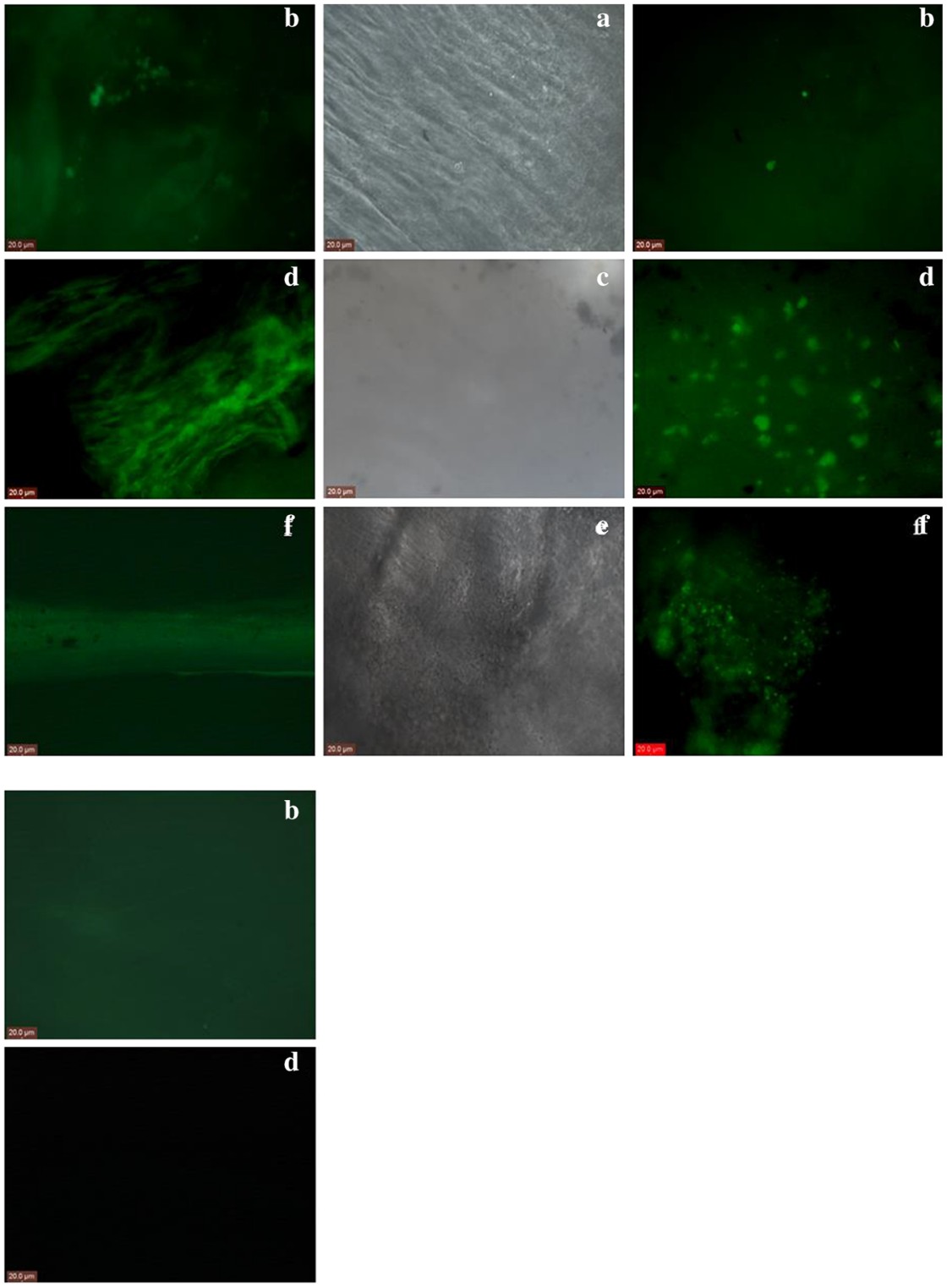

and hepatopancreas, and $b, d$, and $f$ the corresponding GFP expression. C Transduced $P$. monodon with wild-type baculovirus containing GFP (control); $a, c$ and $e$ phase contrast images of gills, haemocytes and hepatopancreas, and $b, d$ and $f$ the same tissue/cells under fluorescence microscope (scale bar 20 $\mathrm{mm}$ ). Images were taken 3 days post infection under microscope $(\times 20$ magnifications) 
BacP2-GFP, respectively, could control transcriptional initiation in shrimp cells in vitro and in vivo. However, the transduction efficiency was around 10-20\% in shrimp cells with the hybrid promoter systems. Further improvisation in transduction can be achieved in the presence of histone deacetylase inhibitors such as sodium butyrate. Guo et al. (2010) proved that sodium butyrate enhanced the expression of baculovirus-mediated sodium/iodide symporter gene in A549 lung adenocarcinoma cells. Many other earlier reports have also pointed out that sodium butyrate could significantly enhance baculovirus mediated gene expression in vertebrate cells (Condreay et al. 1999). Meanwhile, Lu et al. (2005) suggested that the low transduction efficiency could be due to the possible inhibition effect of $\mathrm{pH}$ variations in the medium on attachment of baculovirus to the cell membrane. To address this issue in the present study SCCM having high buffering capacity and $\mathrm{pH} 6.8$ was used to favour virus entry and transgene expression.

In conclusion, two recombinant baculoviral transduction vectors (BacIe1-GFP and BacP2-GFP) that carried expression cassettes consisting of a gene encoding GFP as a reporter linked to the hybrid promoter either to PH-Ie1 or PH-P2 were successfully constructed and expressed in an insect cell line and shrimp cells in vivo and in vitro. Because of its successful expression in shrimp cells without any toxicity, these versatile transduction systems could be used for expression of oncogenes or any immortalizing gene like TERT to effect immortalization of shrimp cells. Moreover, these viral vectors can find application in the development of DNA vaccination and generation of transgenic animals.

Acknowledgments This research was supported by the Department of Biotechnology, Government of India (BT/ PR8050/AAQ/03/289/2006 and BT/PR5126/AAQ/3/591/ 2012). The first author thanks DBT for Fellowship.

\section{References}

Airenne KJ, Hiltunen MO, Turunen MP, Turunen AM, Laitinen OH, Kulomaa MS, Yla-Herttuala S (2000) Baculovirusmediated periadventitial gene transfer to rabbit carotid artery. Gene Ther 7:1499-1504

Ando T, Fujiyuki T, Kawashima T, Morioka M, Kubo T, Fujiwara $\mathrm{H}$ (2007) In vivo gene transfer into the honeybee using a nucleopolyhedron virus vector. Biochem Biophys Res Commun 352:335-340
Beljelarskaya SN (2011) Baculovirus expression systems for production of recombinant proteins in insect and mammalian cells. Mol Biol 45:123-138

Black BC, Brennan LA, Dierks PM, Gard IE (1997) Commercialization of baculoviral insecticides. In: Miller LK (ed) The Baculoviruses. Plenum Press, New York, pp 341-387

Carbonell LF, Klowden MJ, Miller LK (1985) Baculovirusmediated expression of bacterial genes in dipteran and mammalian cells. J Virol 56:153-160

Carter BJ (2005) Adeno-associated virus vectors in clinical trials. Hum Gene Ther 16:541-550

Condreay JP, Witherspoon SM, Clay WC, Kost TA (1999) Transient and stable gene expression in mammalian cells transduced with a recombinant baculovirus vector. Proc Natl Acad Sci USA 96:127-132

Cox MMJ (2012) Recombinant protein vaccines produced in insect cells. Vaccine 30:1759-1766

Dhar AK, Lakshman DK, Natarajan S, Allnutt FCT, van Beek NAM (2007) Functional characterization of putative promoter elements from infectious hypodermal and hematopoietic necrosis virus (IHHNV) in shrimp and in insect and fish cell lines. Virus Res 127:1-8

Felder JM, Sutton RE (2009) Lentiviral vectors. In: Templeton NS (ed) Gene and cell therapy. CRC Press, Boca Raton, pp 207-243

Gamble CM, Barton PA (2011) Baculoviral expression of telomerase in primary human fibroblasts to rejuvenate cells for tissue engineering. J Tissue Eng Regen Med. doi:10. 1002/term.447

Gao H, Wang Y, Li N, Peng W-P, Sun Y, Tong G-Z, Qiu H-J (2007) Efficient gene delivery into mammalian cells mediated by a recombinant baculovirus containing a whispovirus ie1 promoter, a novel shuttle promoter between insect cells and mammalian cells. J Biotechnol 131:138-143

Guo R, Yifan Z, Sheng L, Haoping X, Miao Z, Biao L (2010) Sodium butyrate enhances the expression of baculovirusmediated sodium/iodide symporter gene in A549 lung adenocarcinoma cells. Nucl Med Commun 31:916-921

He F, Ho Y-F, Yu L, Kwang J (2008) WSSV ie1 promoter is more efficient than CMV promoter to express H5 hemagglutinin from influenza virus in baculovirus as a chicken vaccine. BMC Microbiol 8:238. doi:10.1186/1471-2180-8-238

Hermonat PL, Muzyczka N (1984) Use of adeno-associated virus as a mammalian DNA cloning vector: transduction of neomycin resistance into mammalian tissue culture cells. Proc Natl Acad Sci USA 81:6466-6470

Hofmann C, Sandig V, Jennings G, Rudolph M, Schlag P, Strauss M (1995) Efficient gene transfer into human hepatocytes by baculovirus vectors. Proc Natl Acad Sci USA 92:10099-10103

Hu GB, Wang D, Wang CH, Yang K-F (2008) A novel immortalization vector for the establishment of penaeid shrimp cell lines. In Vitro Cell Dev-Anim 44:51-56

Huard J, Lochmuller H, Acsadi G, Jani A, Massie B, Karpati G (1995) The route of administration is a major determinant of the transduction efficiency of rat tissues by adenoviral recombinants. Gene Ther 2:107-115

Jayesh P (2013) Development of lymphoid cell culture system from Penaeus monodon and molecular approaches for its transformation. Ph.D. Thesis. Cochin University of Science and Technology, India 
Jayesh P, Seena J, Singh ISB (2012) Establishment of shrimp cell lines: perception and orientation. Indian J Virol 23:244-251

Jayesh P, Seena J, Philip R, Singh ISB (2013) A novel medium for the development of in vitro cell culture system from Penaeus monodon. Cytotechnology 65:307-322

Jayesh P, Philip R, Singh ISB (2015) Multifactorial interaction of growth factors on Penaeus monodon lymphoid cells and the impact of IGFs in DNA synthesis and metabolic activity in vitro. Cytotechnology 67:559-571

Kost TA, Condreay JP (2002) Recombinant baculoviruses as mammalian cell gene-delivery vectors. Trends Biotechnol 20:173-180

Kozarsky KF, Wilson JM (1993) Gene therapy: adenovirus vectors. Curr Opin Genet Dev 3:499-503

Laemmli UK (1970) Cleavage of structural proteins during the assembly of the head of bacteriophage T4. Nature 227:680-685

Lee DF, Chen CC, Hsu TA, Juang JL (2000) A baculovirus superinfection system: efficient vehicle for gene transfer into Drosophila S2 cells. J Virol 74:11873-11880

Leisy DJ, Lewis TD, Leong J-AC, Rohrmann GF (2003) Transduction of cultured fish cells with recombinant baculoviruses. J Gen Virol 84:1173-1178

Lesch HP, Laitinen A, Peixoto C, Vicente T, Makkonen K-E, Laitinen L, Pikkarainen JT, Samaranayake H, Alves PM, Carrondo MJT, Ylä-Herttuala S, Airenne KJ (2011) Production and purification of lentiviral vectors generated in $293 \mathrm{~T}$ suspension cells with baculoviral vectors. Gene Ther 18:531-538

Lin C-Y, Lu C-H, Luo W-Y, Chang Y-H, Sung L-Y, Chiu H-Y, $\mathrm{Hu}$ Y-C (2010) Baculovirus as a gene delivery vector for cartilage and bone tissue engineering. Curr Gene Ther 10:242-254

Liu W-J, Chang Y-S, Wang C-H, Kou G-H, Lo C-F (2005) Microarray and RT-PCR screening for white spot syndrome virus immediate-early genes in cycloheximidetreated shrimp. Virology 334:327-341

Liu CY-Y, Chen H-Z, Chao Y-C (2010) Maximizing baculovirus-mediated foreign proteins expression in mammalian cells. Curr Gene Ther 10:232-241

Lo W-H, Hwang SM, Chuang CK, Chen CY, Hu Y-C (2009) Development of a hybrid baculoviral vector for sustained transgene expression. Mol Ther 17:658-666

Lu L, Wang H, Manopo I, Yu L, Kwang J (2005) Baculovirusmediated promoter assay and transcriptional analysis of white spot syndrome virus orf427 gene. Virol J 2:71. doi:10.1186/1743-422X-2-71

Luo W-Y, Shih Y-S, Lo W-H, Chen H-R, Wang S-C, Wang C-H, Chien C-H, Chiang C-S, Chuang Y-J, Hu Y-C (2011) Baculovirus vectors for antiangiogenesis-based cancer gene therapy. Cancer Gene Ther 18:637-645

Madhan S, Prabakaran M, Kwang J (2010) Baculovirus as vaccine vectors. Curr Gene Ther 10:201-213

Naldini L, Blomer U, Gallay P, Ory D, Mulligan R, Gage FH, Verma IM, Trono D (1996) In vivo gene delivery and stable transduction of nondividing cells by a lentiviral vector. Science 272:263-267

O'Reilly DR, Miller LK, Luckow VA (1992) Baculovirus expression vectors. A laboratory manual. Freeman WH, New York
Oppenheimer DI, MacNicol AM, Patel NH (1999) Functional conservation of the wingless-engrailed interaction as shown by a widely applicable baculovirus misexpression system. Curr Biol 9:1288-1296

Ping W, Ge J, Li S, Zhou H, Wang K, Feng Y, Lou Z (2006) Baculovirus-mediated gene expression in chicken primary cells. Avian Dis 50:59-63

Poluri A, van Maanen M, Sutton RE (2003) Genetic therapy for HIV/AIDS. Expert Opin Biol Ther 3:951-963

Prabakaran M, Madhan S, Prabhu N, Geng GY, New R, Kwang J (2010) Reverse micelle-encapsulated recombinant baculovirus as an oral vaccine against $\mathrm{H} 5 \mathrm{~N} 1$ infection in mice. Antivir Res 86:180-187

Sarkis C, Serguera C, Petres S, Buchet D, Ridet J-L, Edelman L, Mallet J (2000) Efficient transduction of neural cells in vitro and in vivo by a baculovirus-derived vector. Proc Natl Acad Sci USA 97:14638-14643

Shike HS, Dhar AK, Burns JC, Shimuzu C, Jousset FX, Klimpel KR, Bergoin M (2000) Infectious hypodermal and hematopoietic necrosis virus of shrimp is related to mosquito brevidensoviruses. Virology 277:167-177

Smith GE, Summers MD (1989) Method for producing a recombinant baculovirus expression vector. US Patent, 4879236

Song J, Liang C, Chen X (2006) Transduction of avian cells with recombinant baculovirus. J Virol Methods 135:157-162

Sudheer NS, Philip R, Singh ISB (2011) In vivo screening of mangrove plants for anti WSSV activity in Penaeus monodon, and evaluation of Ceriops tagal as a potential source of antiviral molecules. Aquaculture 311:36-41

Syed Musthaq S, Kwang J (2011) Oral Vaccination of Baculovirus-expressed VP28 displays enhanced protection against white spot syndrome virus in Penaeus monodon. PLoS One 6:e26428. doi:10.1371/journal.pone.0026428

Syed Musthaq S, Madhan S, Hameed ASS, Kwang J (2009) Localization of VP28 on the baculovirus envelope and its immunogenicity against white spot syndrome virus in $P e$ naeus monodon. Virology 391:315-324

Tani H, Nishijima M, Ushijima H, Miyamura T, Matsuura Y (2001) Characterization of cell-surface determinants important for baculovirus infection. Virology 279:343-353

Treanor JJ, Schiff GM, Hayden FG, Brady RC, Hay CM, Meyer AL, Holden-Wiltse J, Liang H, Gilbert A, Cox M (2007) Safety and immunogenicity of a baculovirus-expressed hemagglutinin influenza vaccine: a randomized controlled trial. J Am Med Assoc 297:1577-1582

van Oers MM (2006) Vaccines for viral and parasitic diseases produced with baculovirus vectors. Adv Virus Res 68:193-253

Wagle M, Jesuthasan S (2003) Baculovirus-mediated gene expression in zebrafish. Mar Biotechnol 5:58-63

Wagle M, Grunewald B, Subburaju S, Barzaghi C, Le GS, Chan J, Jesuthasan S (2004) EphrinB2a in the zebrafish retinotectal system. J Neurobiol 59:57-65

Wang S, Balasundaram G (2010) Potential cancer gene therapy by baculoviral transduction. Curr Gene Ther 10:214-225

Zeng J, Du J, Lin J, Bak XY, Wu C, Wang S (2009) Highefficiency transient transduction of human embryonic stem cell-derived neurons with baculoviral vectors. Mol Ther $17: 1585-1593$ 
Zhao Y, Lam DH, Yang J, Lin J, Tham CK, Ng WH, Wang S (2012) Targeted suicide gene therapy for glioma using human embryonic stem cell-derived neural stem cells genetically modified by baculoviral vectors. Gene Ther 19:189-200
Zheng H, Liu C, Zhuang J, Yuan S (2010) Baculovirus expression of cloned porcine arterivirus generates infectious particles in both insect and mammalian cells. J Biotechnol 150:251-258 